\title{
3D femoral neck anteversion measurements based on the posterior femoral plane in ORTHODOC ${ }^{\circledR}$ system
}

\author{
Yeon Soo Lee $\cdot$ Seung Hoon Oh $\cdot$ Jong Keun Seon • \\ Eun Kyoo Song · Taek Rim Yoon
}

Published online: 19 January 2007

(C) International Federation for Medical and Biological Engineering 2007

\section{Erratum to: Med Bio Eng Comput 44(10):895-906 DOI 10.1007/s11517-006-0104-7}

Unfortunately, an error occurred in the left table of Fig. 1. FCA should be PCA which represents "Posterior condylar axis".

Another error occurred in the Abstract, Fig. 7, and legend of Fig. 7:

$\theta^{\circ}=25.3(L / D)-5.4$ in $L / D=0.1 \sim 0.6$ should be $\theta^{\circ}=25.3(L / D)+5.4$ in $L / D=0.1 \sim 0.6$.

Figure 6 is incorrect. The correct version is given below.

The online version of the original article can be found at http://dx.doi.org/10.1007/s11517-006-0104-7.

\section{Y. S. Lee}

Department of Information and Mechatronics Engineering, GwangJu Institute of Science and Technology,

GwanJu, Republic of Korea

e-mail: biomechanics.yslee@gmail.com; yeonslee@gist.ac.kr

\section{J. K. Seon · E. K. Song - T. R. Yoon}

Center for Joint Disease,

Chonnam National University Hwasun Hospital,

Ilsimli 160, Hwasungun, Jeollanamdo 519-809,

Republic of Korea

E. K. Song · T. R. Yoon $(\bowtie)$

Department of Orthopaedic Surgery, Medical School,

Chonnam National University, GwangJu 519-809,

Republic of Korea

e-mail: tryoon@chonnam.ac.kr

S. H. Oh

Rocom Frontier Co Ltd,

Seoul, Republic of Korea

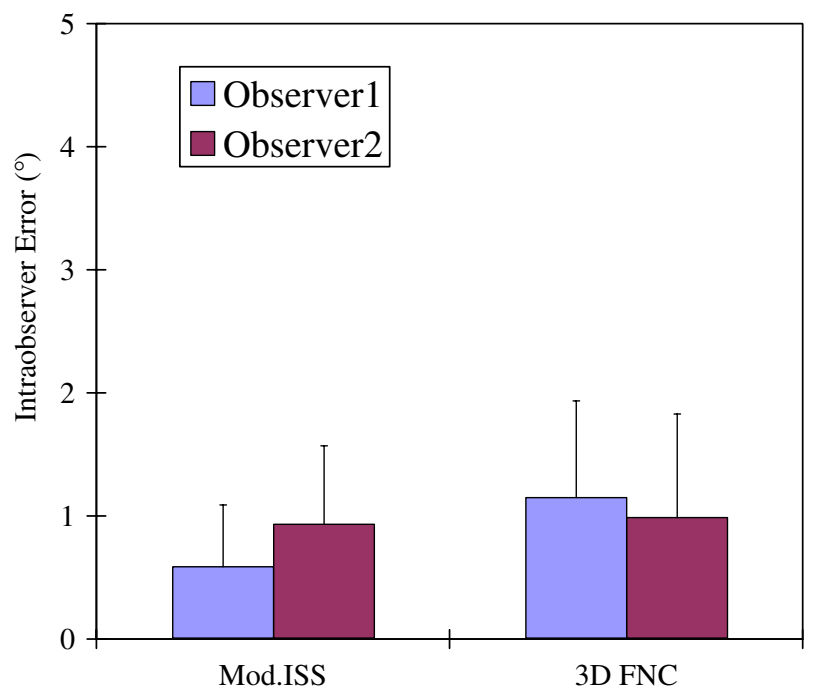

Fig. 6 The measured FNAA by the ISS method and the 3D FNC method. a Shows the interobserver measurement error was expressed. b Shows the intraobserver measurement error for those two methods. Error bars on $\mathbf{a}$ and $\mathbf{b}$ are represented by the standard deviation 